ORIGINAL

\title{
Evaluación in vivo de Lactobacillus plantarum como alternativa al uso de antibióticos en lechones
}

\section{In vivo evaluation of Lactobacillus plantarum as an alternative to antibiotics uses in piglets}

\author{
Henry Jurado-Gámez, ${ }^{1 *}$ Ph.D, Cristina Ramírez T, ${ }^{2}$ Ph.D, Javier Martínez B, ${ }^{1}$ M.Sc.
}

\begin{abstract}
${ }^{1}$ Universidad de Nariño, Facultad de Ciencias Pecuarias, Departamento de Producción y Procesamiento Animal, Programa de Zootecnia. Pasto, Colombia. Grupo de Investigación en Procesos Biotecnológicos Aplicados en la Producción Animal. ${ }^{2} U$ niversidad del Valle, Escuela de Ingeniería de Alimentos, Grupo de Investigación en Ingeniería de los Procesos Agroalimentarios y Biotecnológicos GIPAB. Cali, Colombia. *Correspondencia: henryjugam@gmail.com
\end{abstract}

Recibido: Abril de 2012; Aceptado: Enero de 2013.

\section{RESUMEN}

Objetivos. Evaluar el efecto in vivo de Lactobacillus plantarum como alternativa al uso de antibióticos en lechones. Materiales y métodos. 50 lechones fueron distribuidos en 5 tratamientos $(n=10)$. (T0: sin probiótico; T1: con L. plantarum $1 \mathrm{H} 1$; T2: con L. plantarum $1 \mathrm{H} 2$; T3: con probiótico comercial; T4: sin probiótico comercial). Las cepas fueron identificadas molecularmente. Para la elaboración de los inóculos se utilizaron $10 \mathrm{~g} / \mathrm{L}$ azúcar blanco; $15 \mathrm{~g} / \mathrm{L}$ leche de soya; $150 \mathrm{~g} / \mathrm{L}$ suero de leche; 15 $\mathrm{g} / \mathrm{L}$ salvado de trigo y se analizó la viabilidad a temperatura ambiente y refrigeración. El efecto de los inóculos probióticos se evaluó en ganancia de peso, sobrevivencia y presentación de diarrea. La determinación del contenido de inmunoglobulina A se hizo por turbidimetría; colesterol total y BUN por espectofotometría. El recuento de polimorfonucleares neutrófilos mediante extendido de sangre. Resultados. Las cepas correspondieron molecularmente a Lactobacillus plantarum. La producción de los inóculos, para el caso de L. plantarum $1 \mathrm{H} 1$ y L. plantarum $1 \mathrm{H} 2$ se almacenaron por 21 y 12 días a temperatura de refrigeración manteniendo viabilidades altas. Los animales sometidos a los tratamientos T1 y T2 no presentaron episodios de diarrea y la mayor ganancia de peso vivo final, así como las concentraciones más altas de IgA, polimorfonucleares neutrófilos, colesterol total y BUN fueron menores en T1 y T2. Se comprobó la adherencia de L. plantarum $1 \mathrm{H} 1$ y L. plantarum $1 \mathrm{H} 2$ en el intestino grueso. Conclusiones. La utilización de probióticos con L. plantarum 1 mostraron un efecto positivo en la salud, sobrevivencia y ganancia de peso de los lechones tratados.

Palabras clave: Diarrea, Lactobacillus plantarum, probióticos, tratamientos (Fuentes: CAB). 


\begin{abstract}
Objectives. To evaluate the in vivo effect of Lactobacillus plantarum in piglets as an alternative to antibiotics. Materials and methods. Fifty piglets were allocated into $5(n=10)$ treatment groups (T0: without probiotics; T1: with L. plantarum $1 \mathrm{H} 1$; T2: with L. plantarum $1 \mathrm{H} 2$; T3: with commercial probiotics; T4: without commercial probiotics). The strains were molecularly identified. The inoculate preparation used was $10 \mathrm{~g} / \mathrm{L}$ white sugar, $15 \mathrm{~g} / \mathrm{L}$ soy milk, $150 \mathrm{~g} / \mathrm{L}$ whey, $15 \mathrm{~g} / \mathrm{L}$ wheat bran, analyzing their feasibility at room temperature and refrigeration. The probiotics inoculate were evaluated in weight gain, survival and presentation of diarrhea. Immunoglobulin A was evaluated by turbidimetry, total cholesterol and BUN by spectrophotometry. The count of neutrophils by blood extension. Results. The Lactobacillus plantarum strains corresponded molecularly. The production of inoculate for the case of L. plantarum $1 \mathrm{H} 1$ and L. plantarum $1 \mathrm{H} 2$ was stored for 21 and 12 days in a refrigerated environment while maintaining high viabilities. T1 and T2 had no episodes of diarrhea and higher final live weight gain and higher concentrations of IgA, and polymorphonuclear neutrophil. Total cholesterol and BUN were lower in T1 and T2. We confirmed the accession of L. plantarum $1 \mathrm{H} 1$ and L. plantarum $1 \mathrm{H} 2$ in the intestine. Conclusions. The use of probiotic $L$. plantarum 1 showed a positive effect on the health, survival and weight gain of the piglets treated.
\end{abstract}

Key words: Diarrhea, Lactobacillus plantarum, probiotics, treatment (Sources: CAB).

\section{INTRODUCCIÓN}

El destete de los lechones ocasiona estrés y cambios en su inmunidad, presentando desequilibrio en su microflora intestinal ya que patógenos como Escherichia coli, Clostridium perfringens, Salmonella spp., y rotavirus colonizan el tracto gastrointestinal; causando diarrea post destete (1). Los antibióticos han sido utilizados para prevenir infecciones entéricas, sin embargo, los patógenos desarrollan resistencia cruzada (2) con implicaciones negativas para la salud humana y animal.

Una alternativa al uso de antibióticos, es la utilización de microorganismos vivos con características probióticas en la dieta que depende en parte de la cepa utilizada, pues, no todas tienen la misma capacidad de modulación de la microflora intestinal o la misma capacidad para unirse a las células intestinales. Lactobacillus plantarum se ha utilizado en cerdos para el control de bacterias entéricas (3), e influenciar las comunidades gastrointestinales.

En este estudio se propuso la sustitución o complemento al uso de antibióticos mediante la utilización de inóculos probióticos de Lactobacillus plantarum junto con la ración de iniciación libre de antibióticos en fase de precebo y así, lograr un mejor control de las infecciones que causan diarrea. Además, se evaluó su efecto en los pesos vivos finales, niveles de inmunoglobulina A, colesterol total y nitrógeno ureico, eficacia de la colonización por microscopía electrónica de alta resolución y análisis microbiológicos de muestras histológicas del intestino grueso y materia fecal en los grupos seleccionados.

\section{MATERIALES Y MÉTODOS}

Sitio de estudio. El presente estudio se realizó en el Laboratorio de Microbiología de la Universidad del Valle, sede de Meléndez (Cali, Colombia), y en la finca "La Sierra", (Candelaria, Valle del Cauca, Colombia).

Identificación molecular de Lactobacillus plantarum. Mediante amplificación del gen ribosomal $16 \mathrm{~S}$ por la técnica del PCR, utilizando como molde el DNA genómico extraído directamente de las muestras. Los primers (oligonucleótidos sintéticos) utilizados para la reacción del PCR fueron p27f y p1401r, homólogos a las extremidades conservadas del gen RNA ribosomal $16 \mathrm{~S}$ de bacterias. Estos análisis fueron efectuados en el Centro Pluridisciplinar de Pesquisas Químicas, Biológicas y Agrícolas (PQBA) de la Universidade Estadual de Campinas, São Paulo, Brasil.

Tratamientos. Se trabajó con un total de 50 lechones, distribuidos en cinco tratamientos, 10 lechones por tratamiento: T0 (Control) sin adición de probiótico ni antibiótico, únicamente con concentrado de iniciación; T1: L. plantarum 1 $H 1$, y concentrado de iniciación; T2: L. plantarum $1 \mathrm{H} 2$, y concentrado de iniciación; T3: probiótico comercial, y concentrado de iniciación; T4: Sin adición de probiótico. Se usó el concentrado de preiniciación e iniciación con antibióticos como promotores de crecimiento.

Se evaluaron los diferentes tratamientos por un período de seis semanas, que correspondió a la duración de la fase de precebo. 
Elaboración de inóculos. Utilizando el medio de cultivo seleccionado conocido para este ensayo como medio 4 (10 g/L azúcar blanco; $15 \mathrm{~g} / \mathrm{L}$ leche de soya comercial; $150 \mathrm{~g} / \mathrm{L}$ suero de leche pasteurizado; $15 \mathrm{~g} / \mathrm{L}$ salvado de trigo comercial). Para el proceso de elaboración la fermentación se interrumpió al final de la fase logarítmica a temperatura ambiente $\left(29.5^{\circ} \mathrm{C}\right)$ y refrigeración $\left(4^{\circ} \mathrm{C}\right)$ por 3 semanas, en volúmenes de $250 \mathrm{ml}$ y $2 \mathrm{~L}$, midiéndose la viabilidad en UFC/ml.

Inclusión de los probióticos en la ración. Se procedió a evaluar los probióticos de $L$. plantarum y probiótico comercial a nivel de laboratorio, antes y después de su inclusión en la ración de iniciación. La cantidad de inóculo probiótico añadido (relación $\mathrm{v} / \mathrm{p}$ ) fue del $20 \%(\mathrm{v} / \mathrm{v})$, según lo recomendado por otros autores (4). El probiótico comercial, se suministró siguiendo las instrucciones para su adición.

La inclusión de los probióticos se realizó mezclando los inóculos de $L$. plantarum con el concentrado de iniciación, con una población microbiana producida durante la fermentación no menor de $10^{9} \mathrm{UFC} / \mathrm{ml}$. No se trabajó con el concentrado de pre-iniciación recomendado para las primeras cuatro semanas después del destete, por cuanto contenía antibióticos.

Posteriormente, se introdujo el concentrado en bolsas plásticas selladas al vacío; se las incubó por 3 días a $32^{\circ} \mathrm{C}$. Finalmente, se procedió a suministrarla a los animales directamente en los comederos de tolva durante toda la duración del experimento, es decir, por un período de seis semanas.

Ensayos de desafío in vivo. Los animales utilizados fueron de la misma edad al momento del destete (28 días), machos, cuyo rango de peso vivo al inicio del experimento estuvo entre 8.05 y $8.1 \mathrm{~kg}$ y condiciones de manejo homogéneas, en donde el sistema de alimentación se basó en el suministro del alimento directamente en los comederos de tolva y repartido con una frecuencia de 3 veces al día por las primeras cuatro semanas y luego dos veces al día en las dos últimas semanas. La inclusión de los probióticos en la ración se realizó por mezclado directo de los inóculos con una población microbiana producida durante la fermentación no menor de $10^{9} \mathrm{UFC} / \mathrm{ml}$, para poder conseguir posteriormente poblaciones mínimas de $10^{7} \mathrm{UFC} / \mathrm{g}$ en la ración de iniciación, de modo que continúen presentando una viabilidad adecuada, para de esta manera, ser suministrada a los lechones destetos. El suministro de estos inóculos probióticos junto con la ración y las diferentes mediciones del experimento se hicieron durante un período de seis semanas.
Evaluación del efecto de las cepas probióticas seleccionadas en la ganancia de peso, sobrevivencia y presentación de diarrea en diferentes tratamientos. Se tomaron datos semanales comenzando desde el primer día de inicio del experimento relacionados con sobrevivencia, mortalidad, consumo y conversión alimenticia de los lechones. El diagnóstico de las diarreas se basó en parámetros como: heces líquidas, olor e identificación microbiológica hecha en laboratorio.

Evaluación del efecto inmunoestimulante. Mediante la técnica de turbidimetría se determinó la concentración de inmunoglobulina A.

Evaluación de los niveles de colesterol sérico y nitrógeno ureico en sangre (BUN). Estas muestras fueron tomadas al inicio y final del experimento en ayunas ( 7 a.m.).

Evaluación del epitelio intestinal y colonización por bacterias lácticas. Se realizaron cortes histológicos de ciego, colon transverso y recto de los tratamientos a los cuales se les aplicó el inóculo probiótico, utilizando dos animales por tratamiento mediante microscopia electrónica de alta resolución efectuada en el laboratorio de Microscopía Electrónica de la Universidad del Cauca. La verificación de la presencia y viabilidad de las bacterias ácido-lácticas en el epitelio intestinal se efectuó mediante análisis microbiológico de materia fecal y de intestino de los diferentes tratamientos efectuados.

Diseño y análisis estadístico. Se utilizó un diseño completamente al azar, para un número igual de repeticiones. Las diferencias entre los tratamientos se observaron por la prueba de Duncan usando el paquete estadístico S.A.S. (5).

\section{RESULTADOS}

Los resultados de la identificación molecular indicaron que las secuencias parciales del gen que codifica para el RNA ribosomal $16 \mathrm{~S}$ de las cepas de L. plantarum $1 \mathrm{H} 1$ y L. plantarum 1 $\mathrm{H} 2$ presentaron una similitud del 97 al $99 \%$, y del $95 \%$ respectivamente con las secuencias del gen del RNA ribosomal $16 S$ de los linajes $L$. plantarum, L. pentosus, L. paraplantarum y $L$. plantarum subsp. argentorantensis, incluyendo los linajes tipo cuyos $N^{\circ}$ de acceso Genbak son D79210, D79211, AJ306297 y AJ 640078. También presentaron entre el 99 y $100 \%$ de similaridad con las secuencias del gen RNA ribosomal $16 \mathrm{~S}$ de aislados de Lactobacillus spp., presentes en las bases de datos consultadas Genbak y RDP. 
Para el proceso de elaboración de los inóculos, la fermentación se interrumpió al final de la fase logarítmica, es decir, a las doce horas, y posteriormente, se evaluó la viabilidad (UFC/ml) y $\mathrm{pH}$ a temperatura ambiente $\left(29.5^{\circ} \mathrm{C}\right)$ y refrigeración $\left(4^{\circ} \mathrm{C}\right.$ ) en volúmenes $250 \mathrm{ml}$ y dos litros en períodos de: 12 horas, 7,12 y 21 días para cada volumen.

Los resultados de la fermentación del medio 4 (10 g/L azúcar blanco; $15 \mathrm{~g} / \mathrm{L}$ leche de soya comercial; $150 \mathrm{~g} / \mathrm{L}$ suero de leche pasteurizado; $15 \mathrm{~g} / \mathrm{L}$ salvado de trigo comercial) por un periodo de 12 horas en un volumen de $250 \mathrm{ml}$ indican la alta viabilidad de los inóculos probióticos $L$. plantarum $1 \mathrm{H} 1\left(2.0 \times 10^{14} \mathrm{UFC} / \mathrm{ml}\right.$ con $\mathrm{pH}$ de 3.73 y $9.0 \times 10^{13} \mathrm{UFC} / \mathrm{ml}$ con pH de 3.53 a temperatura de refrigeración y ambiente respectivamente) y $L$. plantarum $1 \mathrm{H} 2\left(2.0 \times 10^{14} \mathrm{UFC} / \mathrm{ml}\right.$ con $\mathrm{pH}$ de 3.68 y 3.51 a temperatura de refrigeración y ambiente respectivamente), confirmando los resultados obtenidos en la cinética y que permitieron escoger este medio 4 como el mejor para la producción de los inóculos, lo que garantizó una alta viabilidad en la ración de iniciación, así como, una buena colonización dado que se instalarían más fácilmente por presentar valores de $\mathrm{pH}$ muy cercanos a los de lechones en fase de precebo.

Al evaluar la viabilidad de las dos bacterias seleccionadas por un período de 7 días, presentaron una alta viabilidad tanto a temperatura de refrigeración como ambiental, con valores de $2.0 \times 10^{14} \mathrm{con} \mathrm{pH}$ de 3.83 y 2.0 $x 10^{12} \mathrm{UFC} / \mathrm{ml}$ con $\mathrm{pH}$ de 3.57 respectivamente para L. plantarum $1 \mathrm{H} 1 \mathrm{y}$, de $2.0 \times 10^{14} \mathrm{con} \mathrm{pH}$ de 3.76 y $4.0 \times 10^{12} \mathrm{UFC} / \mathrm{ml}$ con $\mathrm{pH}$ de 3.57 respectivamente para $L$. plantarum $1 \mathrm{H} 2$.

La viabilidad para un período de 12 días mostró una diferencia marcada, por cuanto $L$. plantarum $1 \mathrm{H} 1$ presentó valores superiores de $6.0 \mathrm{x}$ $10^{13} \mathrm{UFC} / \mathrm{ml}$ en refrigeración, mientras que a temperatura ambiente $\left(25^{\circ} \mathrm{C}\right)$ fue de $1.0 \times 10^{9}$ $\mathrm{UFC} / \mathrm{ml}$. En cuanto al $\mathrm{pH}$, presentaron valores de 3.51 y 3.43 . Para el caso de $L$. plantarum $1 \mathrm{H} 2$ indicó ser de igual manera, más viable en refrigeración $\left(1.0 \times 10^{10} \mathrm{UFC} / \mathrm{ml}\right)$ que a temperatura ambiental $\left(9.0 \times 10^{9} \mathrm{UFC} / \mathrm{ml}\right)$. Para el caso del pH, presentó valores de 3.60 y 3.46 .

Estos resultados dieron el primer parámetro para la producción de los inóculos, ya que permitiría mantener en refrigeración hasta por 12 días los inóculos de $L$. plantarum $1 \mathrm{H} 2$ manteniendo una viabilidad alta y un $\mathrm{pH}$ cercano al de los lechones destetos. Por el contrario, L. plantarum $1 \mathrm{H} 1$ podría ser almacenado por más tiempo en refrigeración dada su alta viabilidad.
Al observar las viabilidades para un período de 21 días, las dos bacterias seleccionadas presentaron altas viabilidades tanto en refrigeración como a temperatura ambiente. Los valores de $\mathrm{pH}$, presentaron un ligero incremento con respecto a los demás períodos de tiempo. Sin embargo, esa variación en el comportamiento de su crecimiento con respecto al período de 12 días, permitió escoger este período de viabilidad en el tiempo para $L$. plantarum $1 \mathrm{H} 2$, ya que garantizaba una constante en el crecimiento logarítmico desde el día 1 hasta el día 12 de almacenamiento en refrigeración.

Los resultados de la fermentación del medio 4 por un período de 12 horas en un volumen de 2 litros indican la alta viabilidad de $L$. plantarum $1 \mathrm{H} 1\left(3.0 \times 10^{14} \mathrm{UFC} / \mathrm{ml}\right.$ con $\mathrm{pH}$ de 4.09 y $2.0 \times$ $10^{14} \mathrm{UFC} / \mathrm{ml}$ con $\mathrm{pH}$ de 4.05 a temperatura de refrigeración y ambiente respectivamente), y de $L$. plantarum $1 \mathrm{H} 2\left(3.0 \times 10^{14} \mathrm{UFC} / \mathrm{ml}\right.$ con $\mathrm{pH}$ de 3.94 y 4.0 a temperatura de refrigeración y ambiente respectivamente), confirmando los resultados obtenidos tanto en un volumen de $250 \mathrm{ml}$ como en la cinética y que confirman que este medio 4 fue el mejor para la producción de los inóculos.

Al evaluar la viabilidad por un período de 7 días, se pudo determinar al igual que en un volumen de $250 \mathrm{ml}$, se mantiene una alta viabilidad tanto a temperatura de refrigeración como ambiental, con valores de $3.0 \times 10^{14} \mathrm{UFC} / \mathrm{ml}$ con $\mathrm{pH}$ de 4.0 y $2.0 \times 10^{14} \mathrm{UFC} / \mathrm{ml}$ con pH de 4.0 respectivamente para L. plantarum $1 \mathrm{H} 1 \mathrm{y}$, de $1.0 \times 10^{14} \mathrm{UFC} / \mathrm{ml}$ con pH de 3.91 y 4.0 para L. plantarum $1 \mathrm{H} 2$.

La viabilidad en el tiempo para un período de 12 días mostraron una diferencia marcada para $L$. plantarum $1 \mathrm{H} 2$, ya que presentó un crecimiento óptimo en refrigeración $\left(5.0 \times 10^{13} \mathrm{UFC} / \mathrm{ml}\right.$ con $\mathrm{pH}$ de 3.95), a diferencia de la temperatura ambiental $\left(2.0 \times 10^{9} \mathrm{UFC} / \mathrm{ml}\right.$ con $\mathrm{pH}$ de 3.94). Estos resultados concuerdan con los obtenidos en un volumen de $250 \mathrm{ml}$ y confirman que para la producción de los inóculos que han de ser incorporados a la ración de iniciación, se pueden mantener en refrigeración hasta por 12 días con L. plantarum $1 \mathrm{H} 2$ y tendrán una viabilidad alta y un $\mathrm{pH}$ casi igual al de los lechones en fase de precebo.

Por el contrario, L. plantarum $1 \mathrm{H} 1$ podría ser almacenado por más tiempo en refrigeración dada su alta viabilidad $\left(1.0 \times 10^{14} \mathrm{UFC} / \mathrm{ml}\right.$ con $\mathrm{pH}$ de 4.09), coincidiendo con los resultados encontrados en un volumen de $250 \mathrm{ml}$. Sin embargo, también mostró una alta viabilidad a temperatura ambiente $\left(1.0 \times 10^{14} \mathrm{UFC} / \mathrm{ml}\right.$ con $\mathrm{pH}$ de 3.85). 
Al observar las viabilidades para un período de 21 días, se pudieron apreciar claras diferencias con respecto a los resultados encontrados en un volumen de $250 \mathrm{ml}$. De esta manera, L. plantarum $1 \mathrm{H} 1$ presentó la viablidad más alta a temperatura de refrigeración $\left(1.0 \times 10^{14} \mathrm{UFC} / \mathrm{ml}\right.$ con $\mathrm{pH}$ de 4.09), que L. plantarum $1 \mathrm{H} 2\left(1.0 \times 10^{10} \mathrm{UFC} /\right.$ $\mathrm{ml}$ con $\mathrm{pH}$ de 4.01). En ambos microorganismos no hubo crecimiento a temperatura ambiental.

Teniendo en cuenta los resultados anteriores, una vez efectuada la fermentación por 12 horas, para el caso de L. plantarum $1 \mathrm{H} 1$ podría ser almacenado hasta por 21 días en refrigeración. Para el caso de L. plantarum $1 \mathrm{H} 2$ se podría almacenar por 12 y 21 días con viabilidades altas. Sin embargo, se tomó la decisión de almacenarlo sólo por 12 días, ya que la fermentación de estos inóculos en el concentrado de iniciación se haría en condiciones de la finca y por lo tanto, no se contaba con un manejo adecuado de variables como temperatura y humedad relativa, ni de incubadoras donde efectuar la fermentación. Además, así se garantiza en parte mayor disponibilidad de sustrato para el crecimiento de L. plantarum $1 \mathrm{H} 2$ (Figuras 1 y 2).

Con respecto a la evaluación de la inclusión de los inóculos probióticos en la ración a nivel de laboratorio por 24 horas, se encontró que $L$. plantarum $1 \mathrm{H} 1$ y L. plantarum $1 \mathrm{H} 2$ mostraron unas viabilidades altas de $2.0 \times 10^{12} \mathrm{UFC} / \mathrm{ml}$ con $\mathrm{pH}$ de 4.01 y $3.0 \times 10^{12} \mathrm{UFC} / \mathrm{ml}$ con $\mathrm{pH}$ de 3.99 respectivamente.

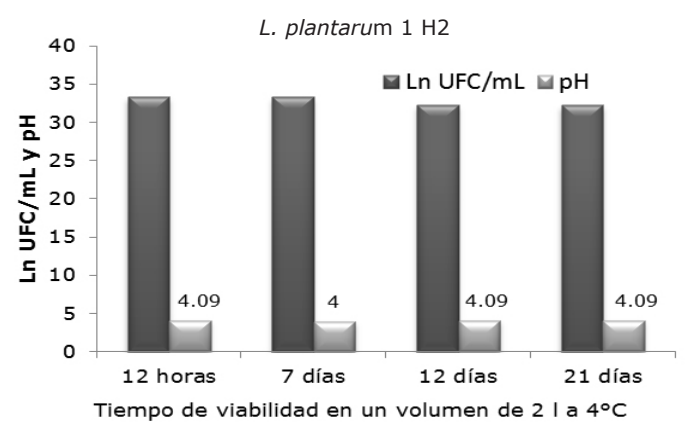

Figura 1. Viabilidad de Lactobacillus plantarum $1 \mathrm{H} 1$.

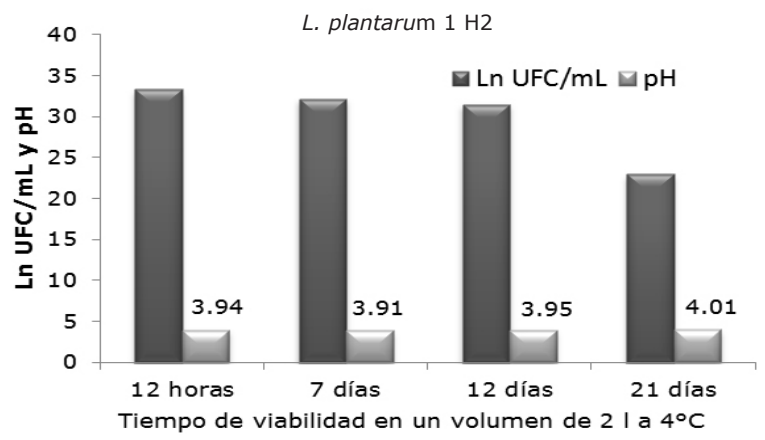

Figura 2. Viabilidad de Lactobacillus plantarum $1 \mathrm{H} 2$.
En la evaluación por 24 horas en la finca, se pudo observar que $L$. plantarum $1 \mathrm{H} 1$ y $L$. plantarum $1 \mathrm{H} 2$ presentaron viabilidades altas de $3.0 \times 10^{14} \mathrm{UFC} / \mathrm{ml}$, con $\mathrm{pH}$ de 3.94 y $\mathrm{pH}$ de 3.95 respectivamente. Al comparar los resultados anteriores, se apreció que las viabilidades fueron similares, considerando las condiciones de finca y los volúmenes inoculados de ración.

En la evaluación por 3 días en la finca, $L$. plantarum $1 \mathrm{H} 1$ y L. plantarum $1 \mathrm{H} 2$ presentaron viabilidades altas de $3.0 \times 10^{14} \mathrm{UFC} / \mathrm{ml}$, con $\mathrm{pH}$ de 4.0 y $\mathrm{pH}$ de 3.99 respectivamente. Esto indica que, además que estos microorganismos colonicen y se adhieran más fácilmente al tracto gastrointestinal de los lechones, también facilitaría el manejo y almacenamiento de esta ración inoculada con probióticos, ya que los volúmenes de concentrado utilizados la producción porcina son elevados.

Los resultados de la viabilidad del probiótico comercial muestran una alta viabilidad en agua estéril con un valor de $8.0 \times 10^{12} \mathrm{UFC} / \mathrm{ml}$, con $\mathrm{pH}$ de 4.0 , con respecto al medio 4 que fue de $1.0 \times 10^{7} \mathrm{UFC} / \mathrm{ml}$, con $\mathrm{pH}$ de 4.2. Esto indica que la elección de este producto comercial de uso veterinario para cerdos fue adecuada como una medida de comparación, especialmente con los inóculos de L. plantarum 1.

En los ensayos de desafío in vivo, fue efectuado un análisis microbiológico para verificar la presencia de bacterias acido-lácticas en las heces de los lechones antes del suministro de las raciones con probióticos, encontrándose que no hubo presencia de BAL, lo cual puede ser característico de lechones destetos, dado el cambio brusco que sufren al cambiar de la fase de lactancia a la de precebo (6).

En cuanto al peso vivo final, existieron diferencias significativas $(p<0.05)$ entre el grupo tratado con Lactobacillus plantarum 1 H2 (T2) y los demás tratamientos (T0, T1, T3 y T4). También se presentaron diferencias significativas $(p<0.05)$ entre el grupo tratado con Lactobacillus plantarum $1 \mathrm{H} 1$ (T1) con respecto a los tratamientos T0, T3 y T4; y entre el tratamiento T4 (Antibiótico) y los tratamientos T0 (Control) y T3 (Probiótico comercial). Entre el tratamiento T3 y T0 no hubo diferencias significativas ( $p>0.05)$.

Para el caso de la ganancia final de peso, existieron diferencias significativas $(p<0.05)$ entre el grupo tratado con Lactobacillus plantarum $1 \mathrm{H} 2$ (T2) y los demás tratamientos (T0, T1, T3 y T4). También se presentaron diferencias significativas $(p<0.05)$ entre el grupo tratado con Lactobacillus plantarum $1 \mathrm{H} 1$ (T1) con respecto a los tratamientos T0 y T3; y entre el tratamiento 
T4 (Antibiótico) y los tratamientos T0 (Control) y T3 (Probiótico comercial). Entre el tratamiento T1 y T4, así como, entre T3 y T0 no hubo diferencias significativas $(p>0.05)$ entre ellos (Tabla 1$)$.

Tabla 1. Peso vivo inicial, peso vivo final y ganancia de peso final en los lechones al final de la fase de precebo.

\begin{tabular}{cccc}
\hline Tratamiento & $\begin{array}{c}\text { Peso Vivo } \\
\text { inicial (kg) }\end{array}$ & $\begin{array}{c}\text { Peso Vivo } \\
\text { final (kg) }\end{array}$ & $\begin{array}{c}\text { Ganancia de Peso } \\
\text { Vivo (kg) }\end{array}$ \\
\hline T0 & $8.05^{\mathrm{a}}$ & $25.75 \mathrm{~d}$ & $17.7 \mathrm{c}$ \\
T1 & $8.1^{\mathrm{a}}$ & $28 \mathrm{~b}$ & $19.9 \mathrm{~b}$ \\
T2 & $8.1^{\mathrm{a}}$ & $29 \mathrm{a}$ & $20.9 \mathrm{a}$ \\
T3 & $8.05^{\mathrm{a}}$ & $26 \mathrm{~d}$ & $17.95 \mathrm{c}$ \\
T4 & $8.05^{\mathrm{a}}$ & $27 \mathrm{c}$ & $18.95 \mathrm{~b}$ \\
\hline
\end{tabular}

Letras diferentes en una misma columna indican diferencias estadísticamente significativas.

El coeficiente de variación presentado en estos valores fue bajo en forma general por debajo del $10 \%$, siendo un coeficiente de variación excelente y que indica que los datos obedecen a condiciones de trabajo uniformes y homogéneas, reduciendo la variación en los resultados.

Los valores de la conversión alimenticia para los tratamientos T0, T1, T2, T3 y T4 fueron respectivamente de: $1.59,1.42,1.35,1.57 \mathrm{y}$ 1.49. Con respecto a la conversión alimenticia, existieron diferencias significativas $(p<0.05)$ entre el grupo control (T0) y los tratamientos T1, T2 y T4. No se presentaron diferencias significativas ( $p>0.05$ ) entre T0 y T3 (probiótico comercial). También hubo diferencias significativas $(p<0.05)$ entre el grupo T3 y los tratamientos T1, T2 y T4. El tratamiento T4 presentó diferencias significativas $(p<0.05)$ con respecto a los tratamientos T1y T2. Finalmente, el tratamiento T1 mostró diferencias significativas $(p<0.05)$ en relación a T2.

La eficiencia con que fue utilizado el alimento por los lechones fue adecuada, en donde los grupos tratados con L. plantarum 1 mostraron la mejor eficiencia en el aprovechamiento del alimento, siendo en todos los casos la media de la conversión alimenticia inferior a 2.0, lo cual se considera óptimo bajo estas condiciones. Además, estos valores de conversión alimenticia están dentro de los parámetros manejados en la finca "La Sierra" de CERVALLE con valores óptimos de 1.5.

Durante el tiempo de utilización de los probióticos de $L$. plantarum $1 \mathrm{H} 1$ y L. plantarum $1 \mathrm{H} 2$ en los tratamientos $\mathrm{T} 1$ y $\mathrm{T} 2$ respectivamente, no se presentaron episodios de diarrea contribuyendo a la mejora de la salud de los animales tratados con respecto a los demás tratamientos, logrando un incremento en el potencial de crecimiento y estimulación de la respuesta inmune de los lechones. Esto se pudo evidenciar, en los casos con episodios de diarrea aguda para los tratamientos: T0 (5), seguido del T3 (3) y el T4 (2), y con una morbilidad del 50,30 y $20 \%$ respectivamente.

Posteriormente se tomó cada tratamiento para cada variable: Concentración de IgA, Concentración de Polimorfonucleares Neutrófilos, Niveles de Colesterol Total y BUN. Cada tratamiento refleja su efecto sobre la variable de respuesta observando la media o mediana, pues bien, los tratamientos T0 y T1 generan diferencias en valor absoluto en su efecto, es decir, en el caso de la concentración de inmunoglobulina el efecto del tratamiento T1 incrementa su valor casi el doble con respecto a la concentración producida por el tratamiento 1. En el caso de niveles de colesterol, el tratamiento T3 difiere significativamente $(p<0.05)$ del tratamiento T2 superándolo en miligramos \%. En BUN el tratamiento T0 generó un efecto mayor en la variable mientras que el tratamiento T3 presentó el menor valor en términos de promedio sobre la misma (Tabla 2).

En la tabla 2 se puede observar como el coeficiente de variación es bajo en forma general por debajo del $10 \%$, siendo un coeficiente de variación excelente y que indica que los datos obedecen a condiciones de trabajo uniformes y homogéneas, reduciendo la variación en los resultados.

Los resultados de la verificación de la presencia y viabilidad de las bacterias ácido-lácticas indicaron valores de $2.35 \times 10^{5} 1.5 \times 10^{5}$ y $8.0 \times 10^{4}$ en ciego, colon transversó y recto respectivamente para el tratamiento T2 (L. plantarum $1 \mathrm{H} 2$ ). Para el T1 (L. plantarum $1 \mathrm{H} 1$ ), presentó valores de $1.0 \times 10^{5} 1.3 \times 10^{5}$ y $1.1 \times 10^{5}$ en ciego, cólon transve'rso y recto respectivamente. En el tratamiento Testigo (TO) no hubo crecimiento de las BAL en las diferentes secciones estudiadas.

Los resultados de la evaluación de epitelio intestinal y adhesión bacteriana de $L$. plantarum $1 \mathrm{H} 1$ y L. plantarum $1 \mathrm{H} 2$, mediante microscopia electrónica se muestran en las figuras 3 y 4 .

Esta adhesión es favorecida gracias a que en los inóculos evaluados la inclusión del prebiótico de salvado de trigo que permite una mejor adhesión de las bacterias al epitelio intestinal. Además que la leche de soya suministra también parte de prebióticos, rafinosa y estaquiosa que favorecen esta adhesión. 
Tabla 2. Media, Mediana, Desviación típica y Coeficiente de variación para cada tratamiento.

\begin{tabular}{cccccc}
\hline Tratamiento & Tamaño & Media & Mediana & Desv. típ. & $\begin{array}{c}\text { Coef. var. } \\
\text { (\%) }\end{array}$ \\
\hline \multicolumn{5}{c}{ Concentración inmunoglobulina A } \\
\hline \multicolumn{5}{c}{ (IgA) } \\
\hline T0 & 3 & 174 & 173 & 2.65 & $1.52 \%$ \\
T1 & 3 & 333 & 332 & 2.65 & $0.79 \%$ \\
T2 & 3 & 300 & 299 & 2.65 & $0.88 \%$ \\
T3 & 3 & 300 & 300 & 1.00 & $0.33 \%$ \\
T4 & 3 & 267 & 267 & 2.00 & $0.75 \%$ \\
Total & 15 & 274.8 & 299 & 56.50 & $20.56 \%$ \\
Concentración polimorfonuclear & neutrófilos & & \\
\hline T0 & 3 & 49 & 48 & 4.58 & $9.35 \%$ \\
T1 & 3 & 55 & 55 & 2.00 & $3.64 \%$ \\
T2 & 3 & 65 & 66 & 2.65 & $4.07 \%$ \\
T3 & 3 & 51 & 50 & 2.65 & $5.19 \%$ \\
T4 & 3 & 60 & 59 & 2.65 & $4.41 \%$ \\
Total & 15 & 56 & 55 & 6.59 & $11.77 \%$ \\
Nivel colesterol total & & & & \\
\hline T0 & 3 & 116.93 & 117.2 & 0.93 & $0.79 \%$ \\
T1 & 3 & 113.83 & 114 & 1.16 & $1.02 \%$ \\
T2 & 3 & 93.80 & 92.8 & 2.65 & $2.82 \%$ \\
T3 & 3 & 137.87 & 138.8 & 1.97 & $1.43 \%$ \\
T4 & 3 & 97.36 & 97.38 & 0.05 & $0.05 \%$ \\
Total & 15 & 111.96 & 114 & 16.37 & $14.62 \%$ \\
Nitrógeno Ureico en Sangre (BUN) & & & \\
\hline T0 & 3 & 9.70 & 9.6 & 0.26 & $2.73 \%$ \\
T1 & 3 & 7.83 & 7.83 & 0.03 & $0.38 \%$ \\
T2 & 3 & 8.76 & 8.75 & 0.04 & $0.41 \%$ \\
T3 & 3 & 7.20 & 7.1 & 0.26 & $3.67 \%$ \\
T4 & 3 & 9.63 & 9.63 & 0.03 & $0.31 \%$ \\
\hline Total & 15 & 8.62 & 8.75 & 1.03 & $11.93 \%$ \\
\hline
\end{tabular}

Las unidades de las variables fueron las siguientes: IgA (VN: hasta $200 \mathrm{mg} / 100 \mathrm{ml}$ ), Polimorfonucleares neutrófilos (VN: $42-75 \%$ ), Colesterol total (VN: Hasta $220 \mathrm{mg} \%$ ) y BUN (VN: Hasta $22 \mathrm{mg} \%$ ).

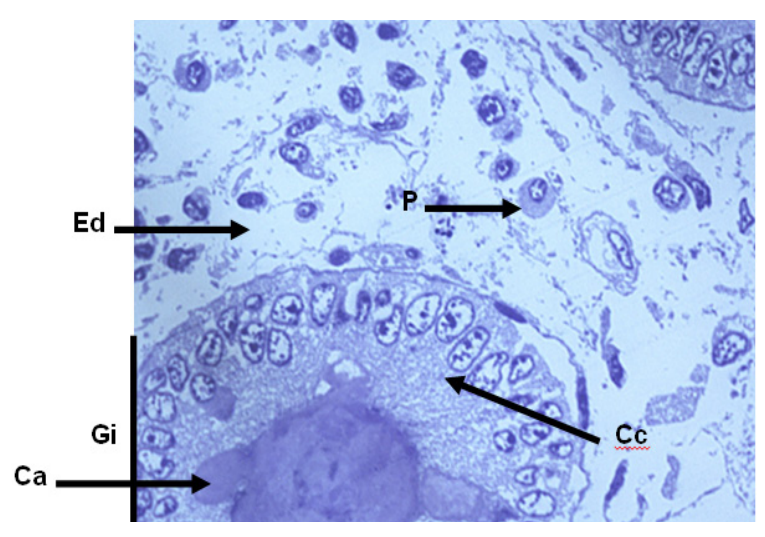

Figura 3. Corte transversal de la mucosa intestinal. En su lámina propia se ven células plasmáticas (P) productoras de anticuerpos, en respuesta a un proceso inflamatorio causado por un agente externo. Se observa edema (Ed) del tejido conectivo como parte de la respuesta inmune. En la parte inferior del corte aparece una glándula intestinal (Gi) compuesta por células cilíndricas $(\mathrm{Cc})$ y células caliciformes (Ca), referente histológico que identifica el intestino grueso. Azul de Toloudina. 100x.

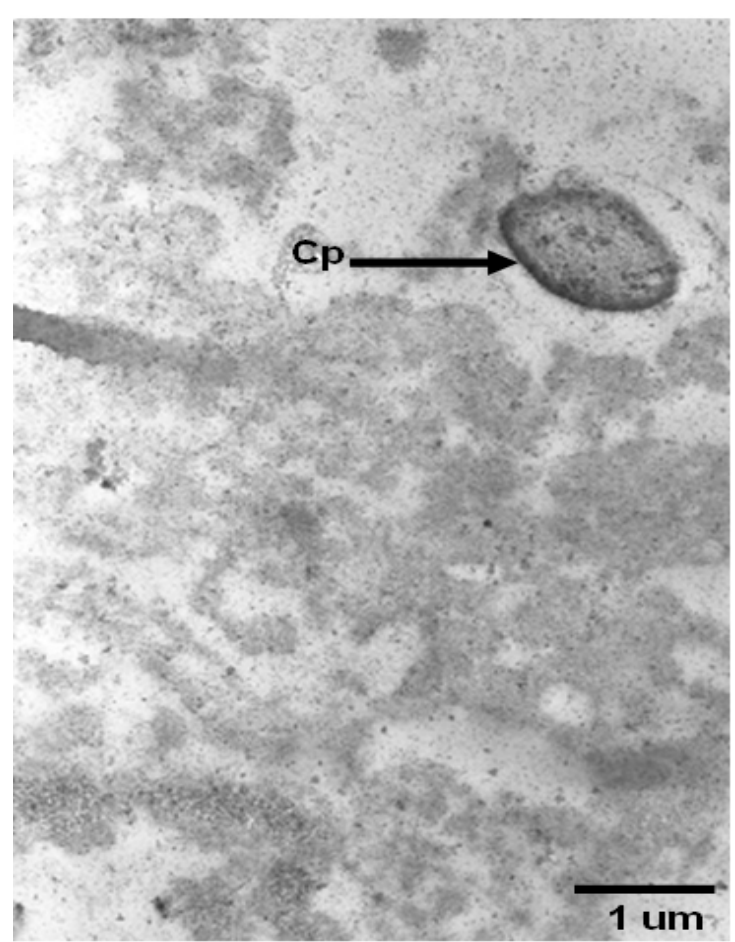

Figura 4. Microfotografía electrónica de la mucosa del intestino grueso del cerdo. Se observa una bacteria de $L$. plantarum $1 \mathrm{H} 2$, en ella se aprecia el material electrodenso que conforma la pared celular.

\section{DISCUSIÓN}

El análisis filogenético confirmó la similaridad de L. plantarum $1 \mathrm{H} 1$ y L. plantarum $1 \mathrm{H} 2$ en un agrupamiento soportado con alto valor de bootstrap $(100 \%)$, relacionado con los linajes tipo de las especies de Lactobacillus plantarum, L. pentosus, L. paraplantarum y L. plantarum subsp. argentorantensis.

La versatilidad de Lactobacillus plantarum se debe al tamaño de su genoma, el cual es 50\% más grande que la mayoría de las BAL y tiene una gran capacidad metabólica, que le permite utilizar una gran variedad de fuentes de carbono; propiedad que resulta de un gran número de genes involucrados en el transporte y utilización de azúcar, y un metabolismo versátil del piruvato, el cual tiene el potencial de producir D y L-lactato, formato, acetato, etanol, acetoína y 2,3butanediol $(7,8)$. Las BAL tienen la capacidad de crecer en una variedad de sustratos $(9,10)$.

Marin et al (9), evaluaron la supervivencia de las cepas Lactobacillus plantarum LPBM10 y Lactobacillus casei ATCC 393, en sustratos de pulpa de uchuva y solución de glucosa (14\% p/p), y almacenamiento a $4^{\circ} \mathrm{C}$ durante 15 días. A los 15 días obtuvieron viabilidades en pulpa y solución 
de glucosa, para L. plantarum de $3.23 \pm 3.35 \times$ $10^{9}$ y $1.64 \pm 1.57 \times 10^{9} \mathrm{UFC} / \mathrm{ml}$, y para $L$. casei de $5.40 \pm 2.36 \times 10^{8}$ y $7.34 \pm 7.88 \times 10^{8}$ UFC/ $\mathrm{ml}$, respectivamente. Los autores concluyeron que con niveles superiores a $10^{6}$, son unos de los criterios considerados para definir un alimento con probióticos. Estos resultados coinciden con los encontrados para un período de 12 días (1112) a temperatura de refrigeración y confirman que $L$. plantarum $1 \mathrm{H} 1$ y especialmente $L$. plantarum $1 \mathrm{H} 2$ son viables a esta temperatura.

Young et al (13) investigaron el efecto de almacenamiento en frio sobre la viabilidad de $L$. plantarum en jugo de tomate fermentado, con viabilidades mayores de $10^{6} \mathrm{UFC} / \mathrm{mL}$ aún después de 4 semanas de almacenamiento a $4^{\circ} \mathrm{C}$. Estos resultados coinciden con los encontrados a los 21 días en la viabilidad de L. plantarum $1 \mathrm{H} 2$ y especialmente para L. plantarum $1 \mathrm{H} 1$ a $4^{\circ} \mathrm{C}$ (14).

La concentración del probiótico comercial que se use es importante y según algunos productos tienen una concentración de $6.0 \times 10^{10} \mathrm{UFC} / 100$ gramos. En cambio, si la viabilidad durante 1 día ó 3 días de fermentación en el medio 4 junto con el concentrado de iniciación mostró un valor de $3.0 \times 10^{14} \mathrm{UFC} / \mathrm{ml}$ y si se toma como ejemplo, 2000 gramos de este concentrado al cual se le adiciona el $20 \%$ de probiótico. Entonces la concentración de los inóculos probióticos (L. plantarum 1) darían un valor de $6.0 \times 10^{15}$ UFC/100 gramos de concentrado de iniciación, presentando una concentración microbiana muy superior comparada con el probiótico comercial. Además, el tipo de microorganismos y la cantidad de estos es muy diferente, por cuanto el producto comercial utiliza las cepas de Bifidobacterium bifidum, L. casei, L. acidophilus y Streptococcus faecium. Los inóculos probióticos estudiados corresponden a una sola cepa usada por separado (15).

Los mejores resultados se encontraron en los lechones que en la fase de precebo recibieron el tratamiento con los probióticos de L. plantarum $1 \mathrm{H} 2$, seguido de L. plantarum $1 \mathrm{H} 1$ (16). Esto coincide con lo reportado por Shim et al (17), según lo cual, los lechones tratados con probióticos asimilan mayor cantidad de nutrientes y aumentan su peso vivo más que aquellos que no fueron tratados (18). Además, mejoran la absorción de nutrientes, la producción de vitaminas y ácidos grasos de cadena corta, que adicionalmente acidifican el lumen intestinal, todo lo cual mejora la digestibilidad de los nutrientes (19).

La metodología usada en esta investigación para el método de inclusión de los probióticos seleccionados en la ración de iniciación y las dosis de UFC/gramo, coinciden con los estudios llevados a cabo por Boucort et al (20). Los probióticos utilizando Lactobacillus mejoran la ganancia diaria de peso y reducen la incidencia de muerte prematura, al establecer una barrera profiláctica contra desórdenes gastrointestinales $(21,22)$.

Un aspecto importante fue la disminución de costos en la alimentación, dado que no se emplearía los antibióticos requeridos para este período de precebo, los cuales representan un valor de US\$292.94 /tonelada de concentrado.

Los probióticos de L. plantarum 1 tuvieron un efecto favorable en la salud de los lechones, por cuanto no se presentaron casos de diarrea durante el experimento, ya que los probióticos tienen una actividad inhibitoria sobre bacterias patógenas, refuerzan la inmunidad mucosal y disminuyen el $\mathrm{pH}$ en el ciego, incrementando los Lactobacillus $(22,23)$.

Cuando el destete ocurre a los 35 días, la altura de las vellosidades se reduce de 410 a $299 \mu \mathrm{m}$ en tan sólo tres días, y es más dramática cuando se desteta a los 21 y 28 días, ocasionando una pérdida en el área de superficie para la absorción de nutrientes caracterizado también por diarreas (24). Estos trastornos podrían ser contrarrestados con la aplicación de inóculos probióticos de L. plantarum 1 en la ración de iniciación, evidenciados en los tratamientos T1 y T2 (25-26). Otros autores como Río-Pérez y Rodríguez-Membribe (27), sostienen que el efecto de los probióticos se da principalmente a nivel de íleon, con un incrementado número de BAL; y en menor proporción, a nivel de ciego y cólon proximal.

Los resultados obtenidos en el estudio constituyen una herramienta valiosa contra el uso indiscriminado de antibióticos en la porcicultura, en donde cada día se buscan nuevas alternativas que promueven una producción más limpia sin el uso de aditivos que pongan en riesgo la salud humana y animal (28).

Mare et al (29) determinaron que L. plantarum 423 se adhería fuertemente al íleon y cólon posterior y L. salivarius 241 al duodeno en los lechones antes del destete. El elevado número de la cepa 241 se adhirió en el duodeno y el colón posterior de los lechones en fase de precebo, mientras que la cepa 423 se localizó en el íleon. Además, estas cepas se adhieren a las diferentes secciones del tracto intestinal, dependiendo de la edad de los lechones. Estos resultados de $L$. salivarius coinciden con el sitio de adhesión de 
L. plantarum $1 \mathrm{H} 1$ y L. plantarum $1 \mathrm{H} 2$ que se identificaron por microscopía electrónica y por los análisis microbiológicos en cólon transverso.

Lactobacillus es altamente efectivo en la colonización de mucosa, tal como el tracto gastrointestinal. Un organismo de administración efectivo debe estar normalmente presente en el tracto gastrointestinal del organismo hospedador y dirigirse con precisión a los sitios mucosales de infección y adherirse a la superficie de las mucosas. Los Lactobacillus poseen ambas características, lo cual permitiría que el $L$. plantarum 1 estudiado en esta investigación, sean de gran utilidad dado que son aislados de la misma especie a la cual se les suministró en la ración de iniciación (30).

\section{Agradecimientos}

A la empresa Cerdos del Valle S.A. (CERVALLE), Cali, Colombia, por la financiación de esta investigación. A la Escuela de Ingeniería de Alimentos; al Dr. Germán Bolívar. A todas personas que de una u otra manera colaboraron para el desarrollo del estudio.

\section{REFERENCIAS}

1. Maxwella FJ, Duncanb SH, Holdc G, Stewartb CS. Isolation, growth on prebiotics and probiotic potential of novel bifidobacteria from pigs. Anaerobe 2004; 10(1):33-39.

2. Figueroa-Velasco JL, Chi-Moreno EE, Cervantes-Ramírez M, Domínguez-Vara IA. Alimentos funcionales para cerdos al destete. Vet Méx 2006; 37(1):117-136.

3. De Angelis $M$, Siragusa $S$, Caputo $L$, Ragni A, Burzigotti R, Gobbetti M. Survival and persistance of Lactobacillus plantarum 4.1 and Lactobacillus reuteri 357 in the gastrointestinal tract of pigs. Vet Microbiol 2007; 123(1-3):133-144.

4. Ramírez C. Uso de bactérias lácticas probióticas na alimentação de camarões Litopenaeus vannamei como inibidoras de microrganismos patogênicos e estimulantes do sistema imune. [Tese de doutorado]. Curitiba: Universidade Federal do Paraná, Setor de Tecnología; 2005.

5. SAS Institute. SAS User's Guide. Stadistics. Version 9.1 2007. Cary: SAS Institute; 2007.

6. Iñiguez C, Perez R, Acedo E. Evaluation of probiotics properties in Lactobacillus isolated from small intestine of pigltes. Rev Latinoam Microbiol 2007; 49: 3-4.

7. Fredricks DN, Fiedler TL, Marrazzo JM. Molecular identification of bacteria associated with bacterial vaginosis. N Engl J Med 2005; 353: 1899-1911.
8. Ljungh A, Wadstrom T. Editores. Lactobacillus Molecular Biology. From Genomics to Probiotics. Norfolk: Caister Academic Press; 2009.

9. Marín Z, Cortés M, Montoya O. Evaluación de la viabilidad de crecimiento de la cepa nativa Lactobacillus plantarum LPBM10 y la cepa comercial Lactobacillus casei ATCC 393 en pulpa de uchuva y en solución isotónica de glucosa. Rev VITAE 2009; 16(2):210-217.

10. Zhan YZ, Bon J, Joan MK. Production of lactic acid from renewable materials by Rhizopus fungi. Chem Eng Process 2006; 46:361-374.

11. González BA, Domínguez R, Alcocer BR. Aloe vera como sustrato para el crecimiento de Lactobacillus plantarum y L. casei. Ciencia y Tecnología Alimentaria 2008; 6(2):152-157.

12. Estela W, Rychtera M, Melzoch K, Quillama E y Egoavil E. Producción de acido láctico por Lactobacillus plantarum L10 en cultivos batch y continuo. Rev Perú Biol 2007; 14(2):271-276.

13. Young K, Woodams E, Hang Y. Fermentation of beet juice by beneficial lactic acid bacteria. J Food Sci Technol 2005; 38(1):73-75.

14. Frede Damgaard. Probióticos en la granja ¿Cómo hacer que trabajen? [En linea]. 2005. URL Disponible en: http://www.aacporcinos. com.ar/nutricion_porcina/probioticos_en_ la_granja.html

15. Plevy S. The immunology of inflammatory bowel disease. Gastroenterol Clin North Am 2002; 31(1):77-92. 
16. Rodríguez JC, Carmenate MC, Hernández JE, Guerra A, Calero I et al. Evaluación del suministro de un preparado biológico de Lactobacillus acidophillus y Streptococcus termophillus en cerdos en crecimiento. Revista Computadorizada de Producción Porcina 2009; 16(1):54-58.

17. Shim SB, Verstegen MWA, Kim IH, Kwon OS, Verdonk JM. Effect of feeding antibiotic-free creep feed supplemented with oligofructose, probiotics or synbiotics to suckling piglets increases the preweaning weight gain and composition of intestinal microbiota. Arch Anim Nutr 2005; 59:419-427.

18. Álvarez JM, Rodríguez JC, Calero I, Hernández JE, Guerra A, Carmenate M et al. Evaluación del suministro de un preparado biológico de Lactobacillus acidophillus y Streptococcus termophillus en cerdos en crecimiento. Revista Computadorizada de Producción Porcina 2009; 16(1):54-58.

19. Amigo S, Laurencio M, Pérez M, Piad R, Milián $\mathrm{G}$ et al. Determinación del contenido de bacterias ácido lácticas y Bacillus del TGI de pollos de ceba y obtención de una mezcla de exclusión competitiva a partir de esta microflora cecal. Rev Cubana Cienc Avícola, 2002; 26:17-22.

20. Boucourt R, Savón L, Díaz J, Brizuela MA, Serrano $P$ et al. Efecto de la actividad probiótica de Lactobacillus rhamnosus en indicadores fisiológicos de lechones. Rev Cubana Ciencia Agrícola, 2004; 38(4):411-416.

21. Benavente D. Efecto del probiótico Sprinter ${ }^{\circledR}$ en lechones recién nacidos. Honduras: Programa de Ingeniería en Ciencia y Producción Agropecuaria. 2003.

22. Marin A, Rodríguez A, Marrero L, Manso MJ y González M. Estudio del efecto en lechones lactantes del probiótico de la biomasa proteica obtenida por la tecnología de cultivo de Lactobacilli y levaduras en miel "B". Liv Res Rural Develop 2007; 19(12):195-196.
23. García Y, García Y, López A, Boucourt R. Probióticos: una alternativa para mejorar el comportamiento animal. Revista Cubana de Ciencia Agrícola 2005; (39)2:129-140.

24. Gómez A, Vergara D, Argote F. Efecto de la dieta y edad del destete sobre la fisiología digestiva del lechón. Rev Bio Agro 2008; 6(1):32-41.

25. Gómez A, Benavides C, Díaz C. Evaluación de torta de palmaste (Elaeis quneensis) en alimentación de cerdos de ceba. Rev Bio Agro 2007; 5(1):54-63.

26. Chinea R, Rodríguez JC, Hernández JE y Calero I. Evaluación de distintos esquemas de aplicación de un probiótico en cerdas paridas con sus crías. En: VII Congreso Centroamericano y del Caribe de Porcicultura; La Habana 30 mayo al 2 junio de 2005. Cuba: VII Congreso; 2005. p. 463-468.

27. RioPérez J y Rodríguez-Membribe ML. Probióticos: Alternativa en la alimentación porcina. Rev Mundo Ganadero 2000; 38-42.

28. Van Heugten E, Funderburke DW and Dorton KL. Growth performance, nutrient digestibility, and fecal microflora in weanling pigs fed live yeast. J Anim Sci 2003; 81:1004-1012.

29. Mare L, Wolfaardt GM, Dicks LMT. Adhesion of Lactobacillus plantarum 423 and Lactobacillus salivarius 241 to the intestinal tract of piglets, as recorded with fluorescent in situ hybridization (FISH), and production of plantaricin 423 by cells colonized to the ileum. J Appl Microbiol 2006; 100(4):838-845.

30. Casas I, Jonsson $H$, Mollstam B, Roos S, inventores; Oficina Española de Patentes y Marcas. Lactobacillus que albergan genes de agregación celular y de fijación de mucina, como vehículos de aporte de vacunas. España patente 09/039.773. 2005. 